\title{
Anaesthetic Challenges in Cardiac Interventional Procedures
}

\author{
Periyasamy Thangavel1, Siva Muthukumar1, Baskar Ranjith Karthekeyan2*, \\ Mahesh Vakamudi², Ashokkumar², Hemananand Nayagam², \\ Kamalakkannan Sambandham ${ }^{2}$ \\ ${ }^{1}$ Department of Cardiac Surgery, Sri Ramachandra University, Chennai, India \\ ${ }^{2}$ Department of Anesthesiology, Sri Ramachandra University, Chennai, India \\ Email: drsamy79@yahoo.com, drsivam@hotmail.com, ’ranjithb73@gmail.com, vakamudi@gmail.com, \\ ashok nermugil@yahoo.com, nayagamam@gmail.com, aneskamal2006@gmail.com
}

Received 9 September 2014; revised 9 October 2014; accepted 31 October 2014

Copyright (C) 2014 by authors and Scientific Research Publishing Inc.

This work is licensed under the Creative Commons Attribution International License (CC BY). http://creativecommons.org/licenses/by/4.0/

(c) (i) Open Access

\section{Abstract}

The increasing scope of interventions in the cardiac catheterization laboratory (CCL) and electrophysiological laboratory (EPL) has resulted in new challenges for the anaesthesia teams where they deal with different patient categories, complications and safety issues. Collaboration and planning between cardiologist and anaesthesiologist are required for both patient safety and procedural success. This review aims to discuss procedures performed in interventional cardiology and the importance of anaesthesiologists in managing such patients. Percutaneous interventions are being increasingly performed in adult as well as in pediatric patients. Procedures are usually done under mild to moderate sedation. General anaesthesia is required in certain conditions and also in pediatric patients. Knowledge of echocardiography, individual disease condition and fluoroscopy is important. Anaesthesiologists are assuming an increasingly important role in the multidisciplinary management of complex patients and interventions. A comprehensive understanding of procedures is essential to provide a high level of anaesthetic care and maintain patient safety.

\section{Keywords}

Cardiac Catheterization, Electrophysiological Laboratory, Percutaneous Interventions, Offsite Anesthesia, Pediatric

\footnotetext{
*Corresponding author.

How to cite this paper: Thangavel, P., Muthukumar, S., Karthekeyan, B.R., Vakamudi, M., Ashokkumar, Nayagam, H. and Sambandham, K. (2014) Anaesthetic Challenges in Cardiac Interventional Procedures. World Journal of Cardiovascular Surgery, 4, 206-216. http://dx.doi.org/10.4236/wjcs.2014.411030
} 


\section{Introduction}

The increasing scope of interventions in the cardiac catheterization laboratory (CCL) has resulted in a work outside the usual operating room environment anaesthesia teams which demands great flexibility in coping with differing patient categories, complications and safety issues [1]. Procedures and interventions in the cardiac catheterization laboratory (CCL) and electrophysiology laboratory (EPL) are more complex and involve acutely ill patients. Collaboration and planning between cardiologist and anaesthesiologist are required for both patient safety and procedural success [2]. Providing safe anaesthesia care to patients undergoing these procedures requires comprehensive preoperative assessment, involvement in the multidisciplinary planning of these cases, and a detailed understanding of the procedures and their potential complications [3].

\section{Anaesthesiologist Approach to Cardiac Catheterisation Laboratory}

Typically there is a control station and procedure room. The control station is shielded from radiation. The anaesthesiologist should familiarize him or herself with each room and particularly the location of gas outlets and suction, monitor for vital signs, cardioverter/defibrillator, emergency medications and any airway equipments normally stored in the room [2]. Locations for a ventilator, anaesthesia cart and possibly a fibre optic cart also should be planned if needed. Other equipment regularly used during cases includes ventricular assist devices and echocardiography. The fluoroscopy table and fluoroscopy equipment are controlled by the cardiologist and can move unexpectedly during the procedure. Long intravenous lines, extra oxygen tubing, and long breathing circuits must be used to allow movement of both the table and fluoroscopy equipment. Having end tidal $\mathrm{CO}_{2}$ monitors in all rooms is important for safe patient care. This would be vastly improved if the normal equipment present in cath lab is described followed by anaesthesia cart stocked with extra intravenous lines, medications and description of what would be the best equipment set up or stock for an anesthesiologist located in the CCL and EPL helps during emergent situations [2] [4].

\subsection{General Anaesthetic Considerations}

There are no established guidelines for anaesthesia consultation in the CCL and EPL [2]. Consultation is based either on patient factors or procedure complexity. Patient airway factors that should trigger an anaesthesia consultation include morbid obesity, obstructive sleep apnea, inability to lie flat, suspected difficult airways, chronic obstructive pulmonary disease, low oxygen saturation, congestive heart failure, hemodynamic instability, psychiatric disorders, morbid obesity and any medication that could complicate administration of sedative agents. Left main coronary artery stenting, investigational percutaneous valve procedure, complex arrhythmia ablation, complicated lead extraction and biventricular pacemaker procedures also should have anaesthetic consultation [2]-[4].

\subsection{Patient}

In the modern cardiac catheterization laboratory, the staff are instructed and trained in basic airway history and exam, and to consult an anaesthesiologist if there is any question about a possible difficult airway. A complete history includes not only the typical evaluation questions but also a comprehensive review of all previous cardiac interventions (diagnostic catheterizations, stent placement and location, left and right sided cardiac pressures, surgical interventions, arrhythmia interventions and ablations), echocardiograms, chest radiographs and any recent changes in the patient's medication regimens. Awareness of the patient's current status of health is imperative. The condition of some patients can be optimized by using diuretics and adjusting medication regimens to optimize respiratory function thereby permitting the patients to lie flat comfortably during the procedure can increase the probability of a successful result [2] [4].

\section{Risk to Anaesthesiologist}

Cancer and genetic injury are unpredictable side effects of ionizing radiation because there is no known safe lower limit of exposure. The SI-derived unit of radiation, the Sievert (Sv), quantifies the biologic effect of ionizing radiation. Sv dose limits are expressed as the equivalent dose (for the dose absorbed in a particular tissue or organ) and the effective dose (for the total weighted sum of an equivalent dose across the entire body). Normal annual background radiation exposure is about $0.5 \mathrm{mSv} /$ year. In the European Union, this is an effective 
dose limit of $20 \mathrm{mSv} / \mathrm{y}$ (averaged over 5 years), with an annual maximum limit of $50 \mathrm{mSv}$. In the United States, the annual occupational limit is $50 \mathrm{mSv}$, and the lifetime limit is $10 \mathrm{mSv}$ multiplied by age in years [3].

There are 3 principles that should be applied to protect staff from radiation: maximize distance from the radiation source, limit the exposure time and use adequate radiation protection. The guiding principle for radiation exposure is the ALARA principle (i.e., As Low As Reasonably Achievable). Minimizing exposure time, maximizing distance from the X-ray source and scatter, use of shields, monitoring of personal exposure through dosimeter use, and education and training should guide anaesthesia practice in these procedural areas. A lead apron covers $82 \%$ of the active bone marrow, which still leaves a significant portion at risk to the effects of radiation. It is highly recommended to wear leaded eye glasses to reduce the risk of cataracts. Moveable lead shields are used for additional protection from direct radiation exposure, but are less effective in protection from radiation scatter [4].

\subsection{Monitoring}

Establishing the best location to view the necessary monitors is essential and may require changing the current room set up. Being able to see the fluoroscopy screen is helpful to monitor the progress of the procedure and anticipate changes in hemodynamics or patient comfort. Electrocardiogram, blood pressure and pulse oximetry are mandatory and for prolonged cases invasive arterial pressure monitoring is necessary. End tidal $\mathrm{CO}_{2}$ monitoring is not required for sedation cases but is recommended for patients who will need deep sedation [5]. The American society of anaesthesiologists has established monitoring guidelines for sedation by anaesthesia and non anaesthesia personnel in non operating room locations [6].

\subsection{Choice of Anaesthesia}

\section{Sedation}

Most procedures in the CCL and EPL are performed using mild to moderate sedation [2] administered by trained personnel and local anaesthetic infiltration at the site of catheter placement by the cardiologist. Non anaesthesia personnel administering mild to moderate sedation should be trained in pharmacology of commonly used agents and be able to recognize and manage respiratory and hemodynamic indicators for mild, moderate and deep sedation [5]. Anaesthesiologists should take an active role in developing and maintaining sedation standard for non anaesthesia personnel throughout the hospital [5]. Patients in the CCL and EPL commonly are sedated with fentanyl and midazolam because of the ease of drug titration and their shorter redistribution and elimination halflives. Deep sedation is necessary only for a couple of minutes during the procedure. Dexmedetomidine is ideal in those having complicated airways or mild respiratory compromise. In patients in the EPL, dexmedetomidine may not be appropriate because it causes sympatholysis, which can be a problem when trying to induce arrhythmias for either diagnosis or treatment.

\section{General Anaesthesia}

For atrial ablation procedures, minimizing patient movement and respiratory motion (which can be significant with a partially obstructed airway in sedated patients) is especially important when 3D guidance systems are used [7]. In a recent prospective, randomized trial of general anaesthesia with endotracheal intubation versus sedation for patients undergoing atrial ablation, the general anaesthesia group had a higher procedural success rate and shorter total duration and fluoroscopy times [8]. General anaesthesia with spontaneous ventilation via a laryngeal mask airway also can provide excellent procedural conditions. When intermittent respiratory pauses are required to reduce movement of the heart, a low dose of muscle relaxant (such as cisatracurium) and gentle controlled ventilation may be used.

\section{Choice of Anaesthetic}

Volatile anaesthetics, including sevoflurane, have been shown to prolong QT intervals [9], and in vitro data show that volatile anaesthetics increase the action potential duration in cloned human cells [10]. Although the clinical significance of these findings is uncertain, it may be prudent to avoid volatile anaesthetics in patients with prolonged QT intervals who are undergoing electrophysiological procedures. QTc may be increased by barbiturates and decreased by propofol. Opioids may attenuate increases in heart rate by increasing parasympa- 
thetic tone. They do not affect the QT interval [11].

\section{Procedure Related Concern}

\subsection{Percutaneous Coronary Intervention}

The first coronary stent was placed in 1986 [12]. Drug eluting stents appear to minimize the complications of in-stent restenosis and neointimal hyperplasia seen with bare metal stents [12]-[14] (Figure 1). Anatomy and lesion of the coronary artery is very important in this interventions (Figure 2 and Figure 3). Percutaneous coronary interventions commonly are performed using mild to moderate sedation under the direction of the cardiologist. Anaesthesia involvement typically occurs in patients presenting with respiratory insufficiency, hemodynamic compromise or emergently during the procedure because of sedation complications or acute patient decompensation. If an airway is to be established placement of an endotracheal tube is preferred to a laryngeal mask airway.

Performing the procedure in patients in cardiogenic shock following an ischemic event often requires endotracheal intubation, not only to secure the airway but also to ensure optimal oxygenation and ventilation. Positive pressure ventilation may also aid a failing left ventricle by reducing after load. Anaesthesia is also required in patients who have suffered an out-of-hospital cardiac arrest, for the institution and maintenance of syste-
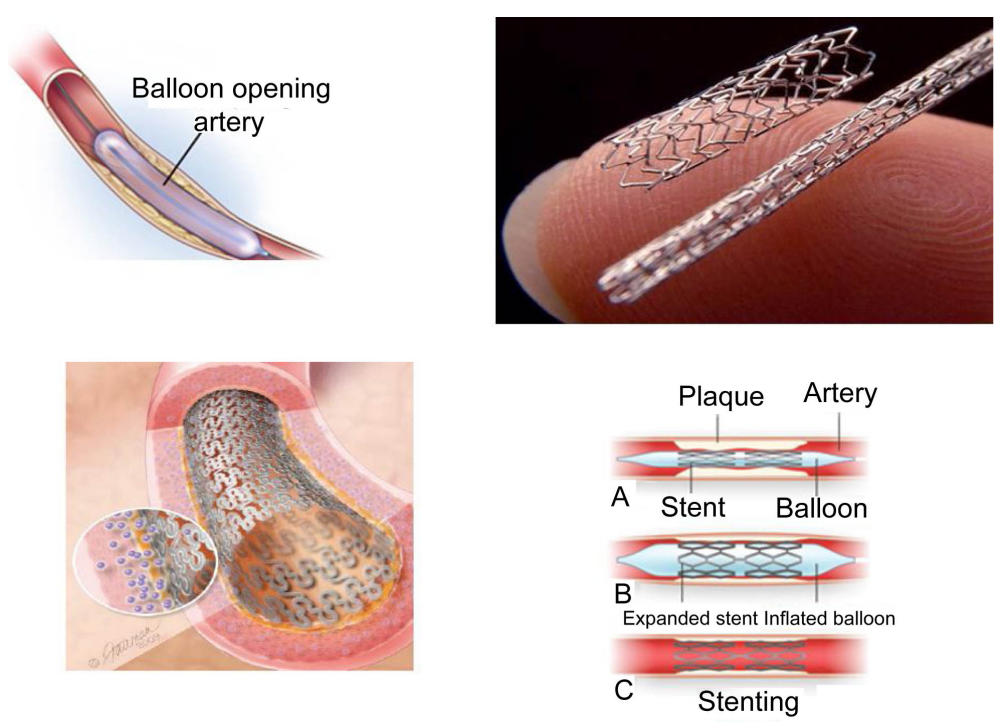

Figure 1. Drug eluting stent and placement of stent in the coronary arteries.

\section{Coronary Angiography}
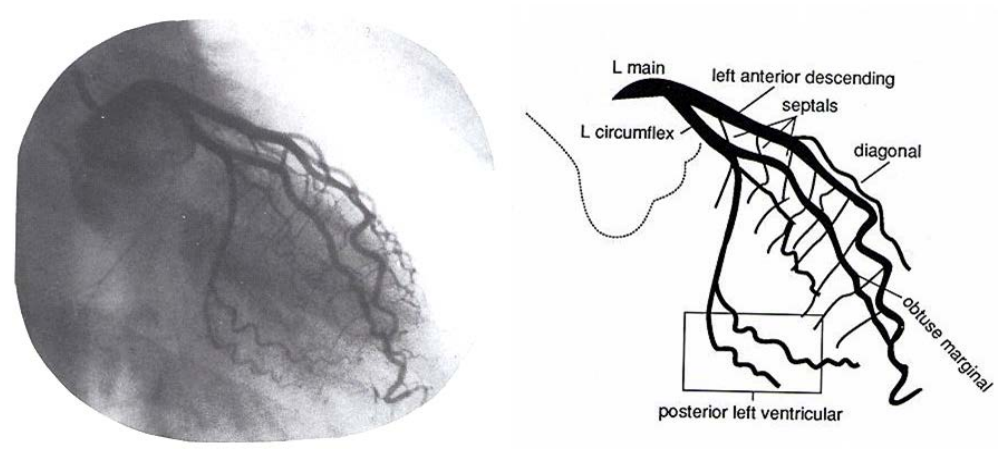

Figure 2. Left coronary artery anatomy and angiogram. 


\section{Coronary Angiography}

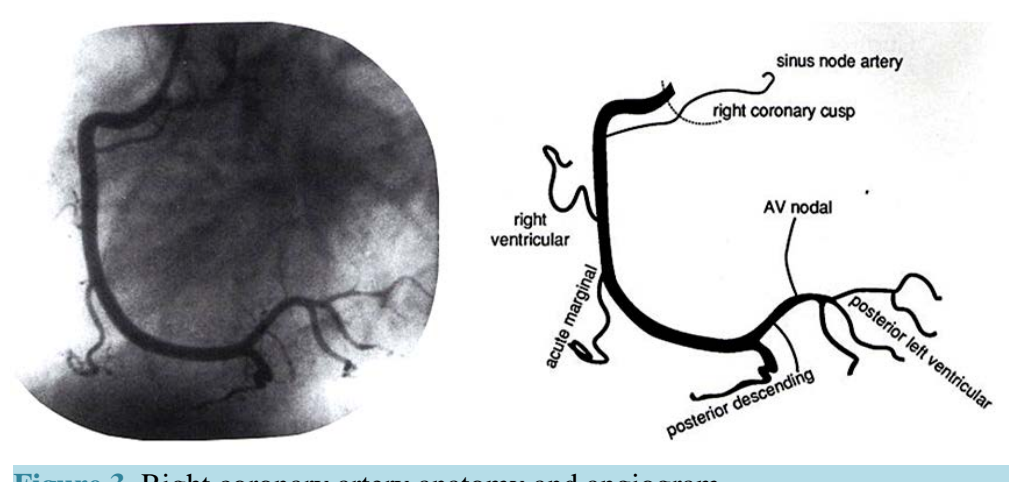

Figure 3. Right coronary artery anatomy and angiogram.

mic hypothermia for cerebral protection [15].

\subsection{Percutaneous Closure of Septal Defects}

The first nonoperative atrial septal defect closure was reported in 1976 [16]. Most of these devices are placed under general anaesthesia with transoesophageal echocardiogram to assist in device placement and evaluation of success (Figure 4). A catheter is passed from the femoral vein to gain access to the right atrium and septal defect. In paediatric population, heart catheterization almost always requires general anaesthesia. Preanaesthesia screening of the patient must involve a detailed analysis of the (suspected) abnormality and consideration must be given to the possible effect of anaesthetic drugs on systemic and pulmonary vascular resistance and the consequences this may have on shunts, preload, systemic flow and pulmonary flow. During the catheterization, attention must be paid to the effects that the maintenance of anaesthesia, mechanical ventilation and inspired oxygen concentrations have on the measurement of flow, pressures and shunts. A detailed review of catheterization, interventional cardiology and ablation techniques for children has recently been published [17].

Challenges to the anaesthesiologist persist even in adult patients in gaining a full understanding of an often complex and possibly previously manipulated circulation. Effects of general anaesthesia and mechanical ventilation on preload, pulmonary vascular resistance and systemic vascular resistance and consequences for the haemodynamic state must be carefully considered. Uncooperative patients present a separate challenge as a gradual induction may not be feasible and preprocedure sedation with the associated side effects on oxygenation and ventilation may occur. Most commonly, a balanced anaesthesia technique is used in these patients. Importantly, in patients with previous right heart exclusion procedures (Fontan circulation) the avoidance of pulmonary hypertension is vital. General anaesthesia is often required for the prolonged, complex interventions or for patients who have associated learning difficulties as a part of a syndrome associated with the congenital heart abnormality. Patients who have post myocardial infarction septal rupture can be hemodynamically unstable and may be more likely to have complications during closure of the defects [18] [19].

\subsection{Percutaneous Valve Repair and Replacement}

The first percutaneous aortic valve replacement was performed in France in 2002 [20]. Percutaneous mitral valve repair with mitraclip or commissurotomy are usually performed under general anaesthesia with guidance from fluoroscopy and transoesophageal echocardiography [21] [22]. Two peripheral intravenous lines or a central line should be placed for infusions and boluses. Endotracheal intubation is preferred and arterial invasive monitoring should be considered depending on the patients ventricular function. Percutaneous aortic valve replacement involves patients who are extremely ill. Patients frequently become hemodynamically unstable during the case and can develop myocardial ischemia and significant arrhythmias. Percutaneously pulmonary as well as tricuspid valve replacements have been done.

Balloon Mitral Valvotomy (BMV) can be done either by antegrade or retrograde approaches (Figure 5). Indications require a suitable anatomy, absence of left atrial clot, mild mitral regurgitation, symptomatic patients 


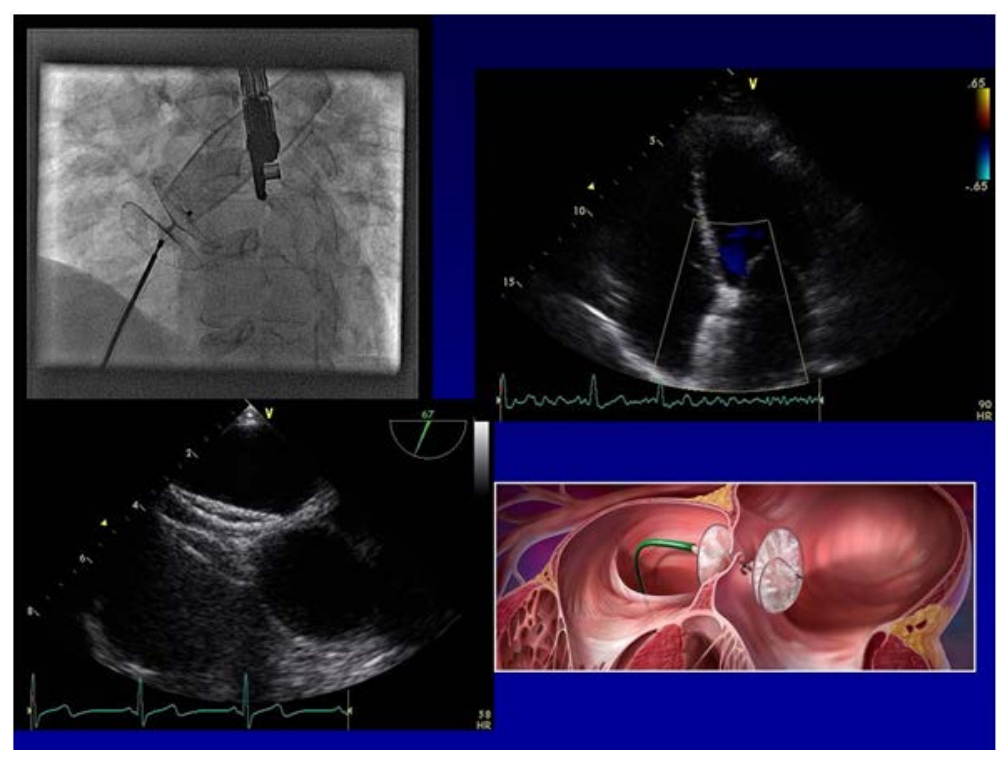

Figure 4. Echocardiogram, fluoroscopy and image of atrial septal defect device closure.
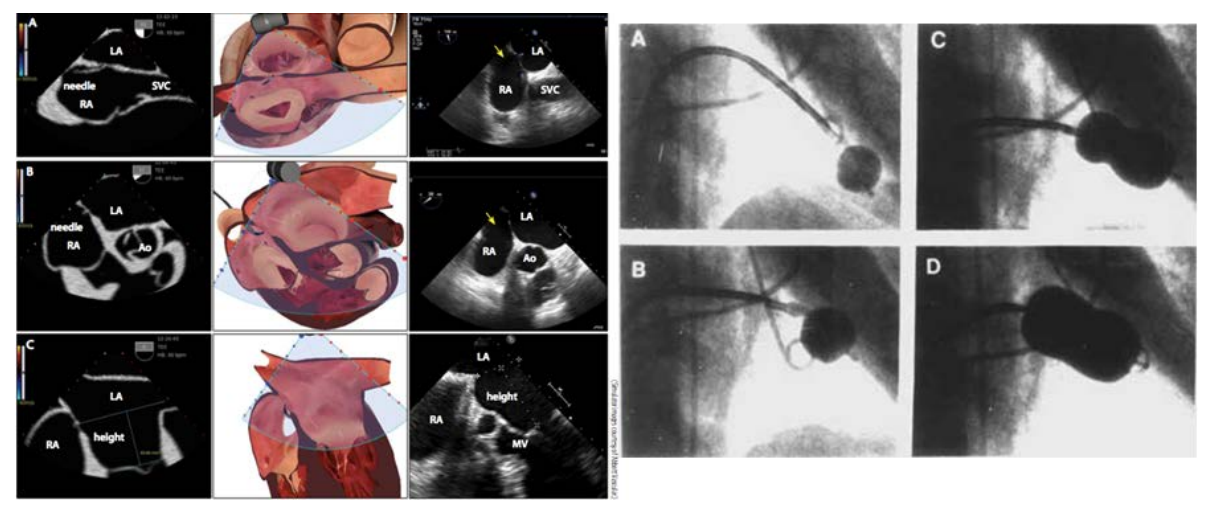

Figure 5. Echocardiogram, fluoroscopy and image of balloon mitral valvotomy.

with mitral vave area $>1.5 \mathrm{~cm}^{2}$ and asymptomatic patients with mitral valve area $<1.5 \mathrm{~cm}^{2}$. Contraindications include calcified mitral valve, mild mitral stenosis, moderate mitral regurgitation and left atrial thrombus formation. Procedure can be concluded if there is adequate increase in valve area, decrease in mitral valve gradient, increase in degree of mitral regurgitation and decreased murmur intensity is present [23].

\subsection{Percutaneous Ventricular Assist Device}

Percutaneous ventricular assist devices (Intraaortic balloon pump, Tandem heart, Impella and left ventricular assist device) are placed in patients undergoing high risk percutaneous coronary interventions or high risk ablation procedures or who are hemodynamically compromised [24] [25]. Venoarterial extracorporeal membrane oxygenation also has been used successfully to support patients undergoing high-risk angioplasty procedures [26]. Depending on the procedure and the state of the patient, either sedation or general anaesthesia can be used to care for the patient safety. Surgical back up is usually necessary during these procedures. The anaesthesiologist should confirm that back up is available.

\section{Catheter Ablation}

An electrophysiology (EP) study is a test that measures how electrical signals move through your heart. Radiofrequency ablation (RFA) is a procedure used to treat some types of heart rhythm problems (Figure 6). Com- 


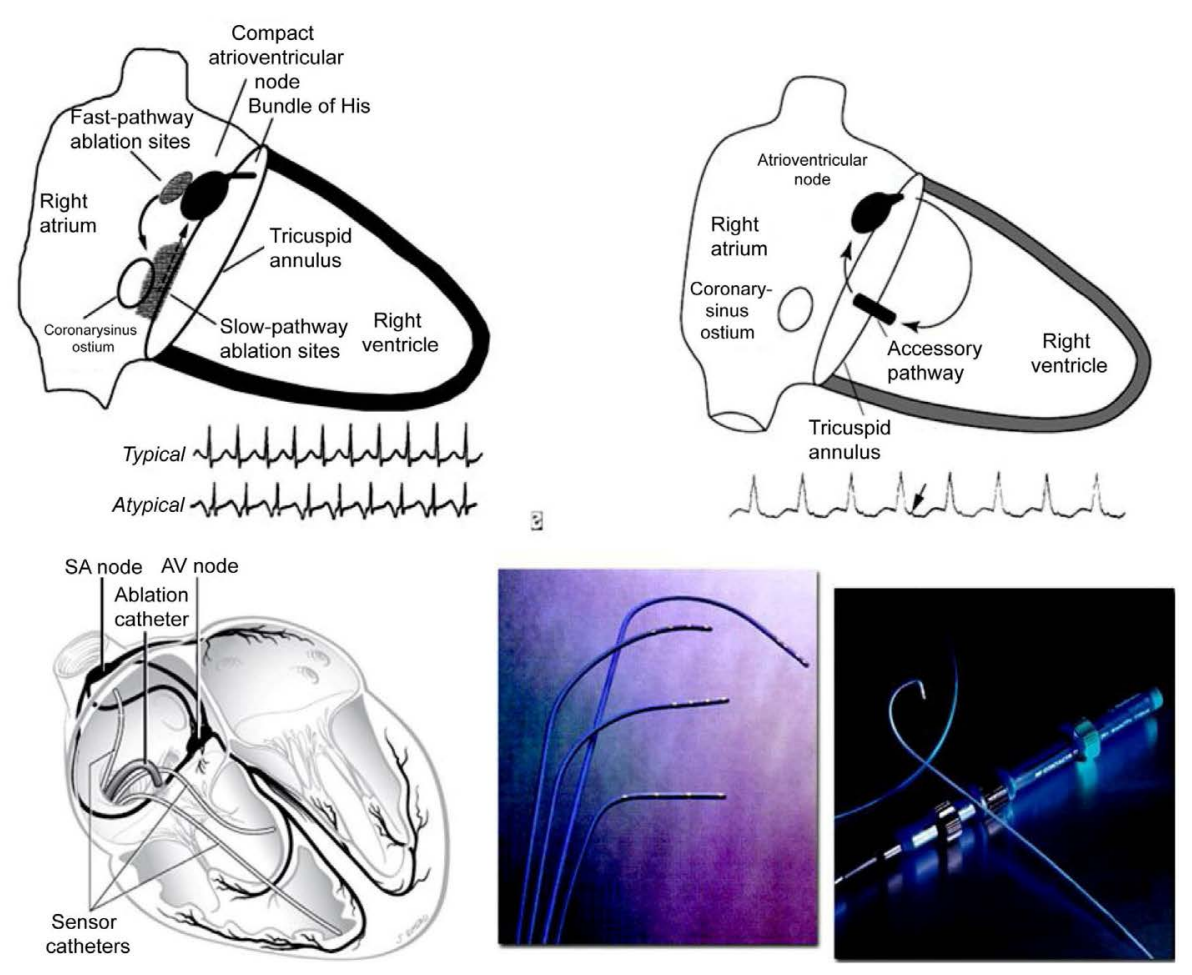

Figure 6. Aberrant pathways and catheters of electrophysiological studies.

pared with other tests, it provides better information about the electrical system of your heart. It accurately diagnose the cause of a heart rhythm problem, find its source and test medications to treat it. Ablation procedure can lessen or eliminate the heart rhythm problem and allow decreasing or stopping long-term medication for a heart rhythm problem. Most catheter ablations are performed with moderate sedation and standard monitoring. Some percutaneous ablation procedures can be very long and may require anaesthesia assistance to keep the patient comfortable for 6 - 8 hours [7]. Coughing, snoring or paradoxical abdominal motion can be problematic during intracardiac mapping. Anaesthetic should not alter intrinsic pacemaker function, impulse propagation, refractoriness or autonomic tone Drugs that affect sympathetic nervous system should be particularly avoided [2] $[4]$.

\section{Pacemakers and Automated Implantable Cardioverter Defibrillator}

Majority of these devices are placed percutaneously under mild to moderate sedation. Pacemaker can be single chambered or dual chambered (Figure 7). Testing the devices requires deep sedation or general anaesthesia as the shocks associated with testing can be painful. External cardioverter defibrillator adhesive pads are placed on the patients. Typically an implanted cardioverter defibrillator is tested twice at the end of the procedure [27] [28]. Patients for biventricular pacemaker lead placement usually will have poor cardiac function. Therefore sedation must be titrated carefully. Pacemakers lead can fracture, insulation can become worn and the leads themselves can lose contact with the myocardium after prolonged use. Treatment of infections sometimes includes the removal of leads. Leads less than 12 months old usually can be removed by simple traction [29]. Laser sheath removal has been available since 2000. If lead removal is done in case of infection, antibiotic prophylaxis atleast 1 hour before skin incision should be given.

\section{PDA Device Closure}

Patent Ductus Arteriosus (PDA) can be closed with devices like coils, Amplatzer duct occlude or Rashkind occlusion device if they are $<1 \mathrm{~cm}$ in diameter (Figure 8 and Figure 9). The larger diameter is usually positioned in the aortic end of the ductal ampulla, while the smaller diameter is positioned at the pulmonary end. Though it can be done under sedation, general anaesthesia is required in case of infants and toddlers [30]. 

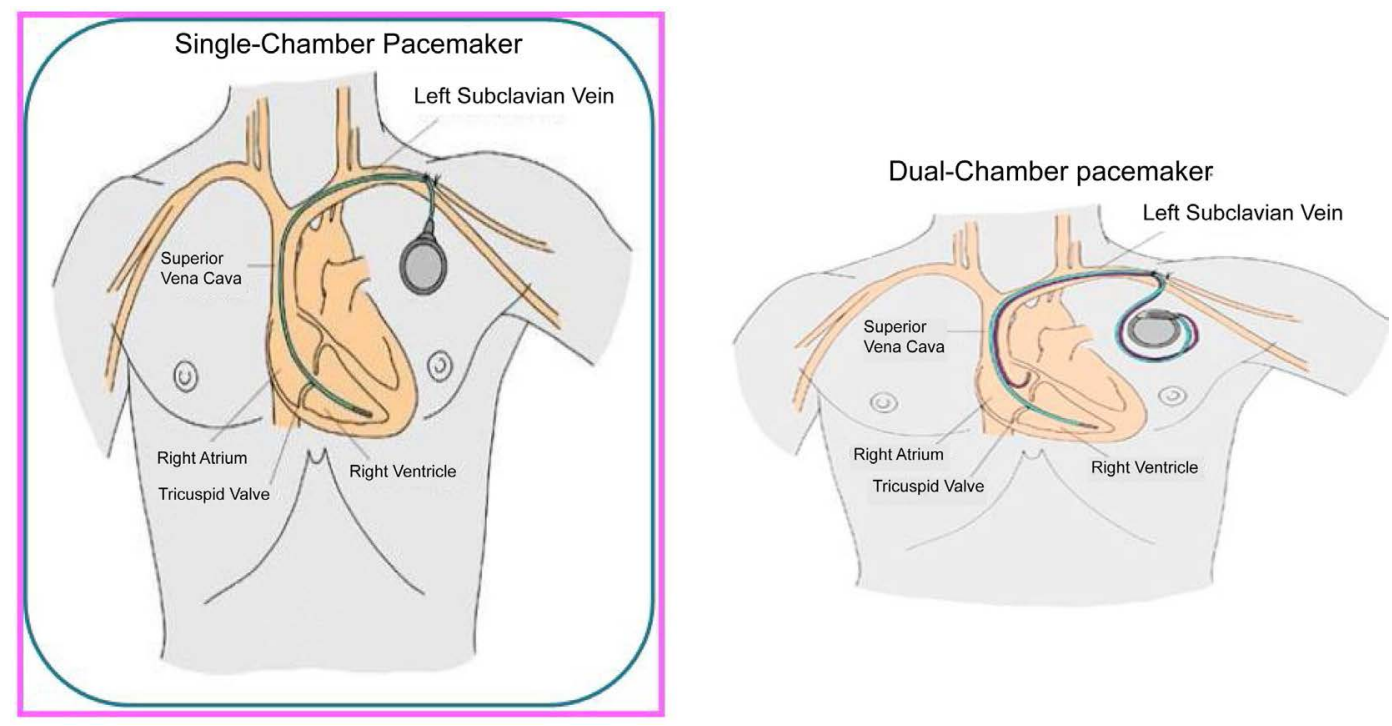

Figure 7. Single and dual chamber pacemaker.

Closure of patent ductus arteriosus (PDA)

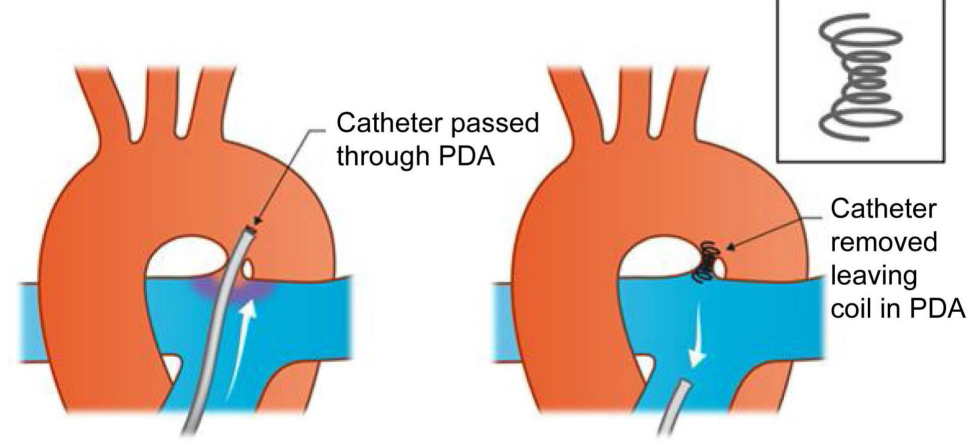

Coil closure of small PDA

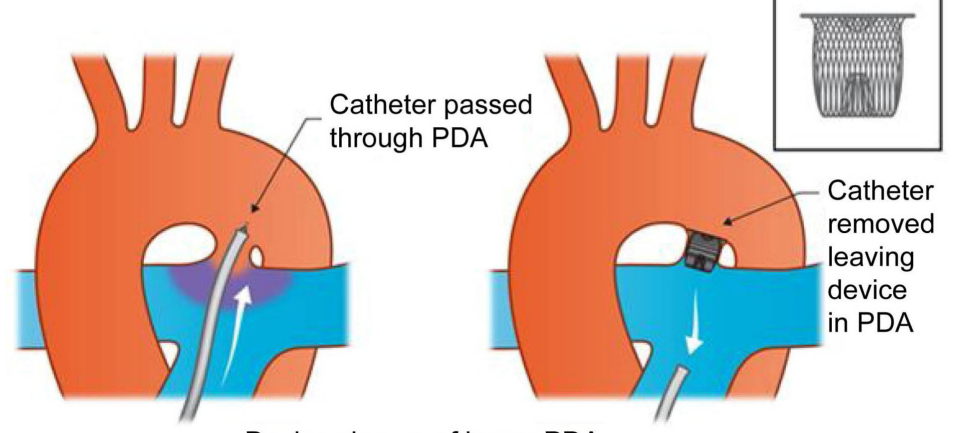

Device closure of larger PDA

Figure 8. Coil and device closure of patent ductus arteriosus.

\section{Limitations of Cardiac Catheterization Laboratory}

Access to the airway of the patient may be extremely limited by the presence of the large C-arm of the fluoroscopy equipment. Requirement of extended ventilation tubing is another problem. Care must be taken to ensure that manipulation of the $\mathrm{C}$-arm does not dislocate the ventilation tubing or airway device. Central venous access may be difficult to obtain as the CCL table can often not be placed in the Trendelenburg position. Connections to pressure lines and intravenous pumps may also have to be extended to allow for the lack of space in the vicin- 


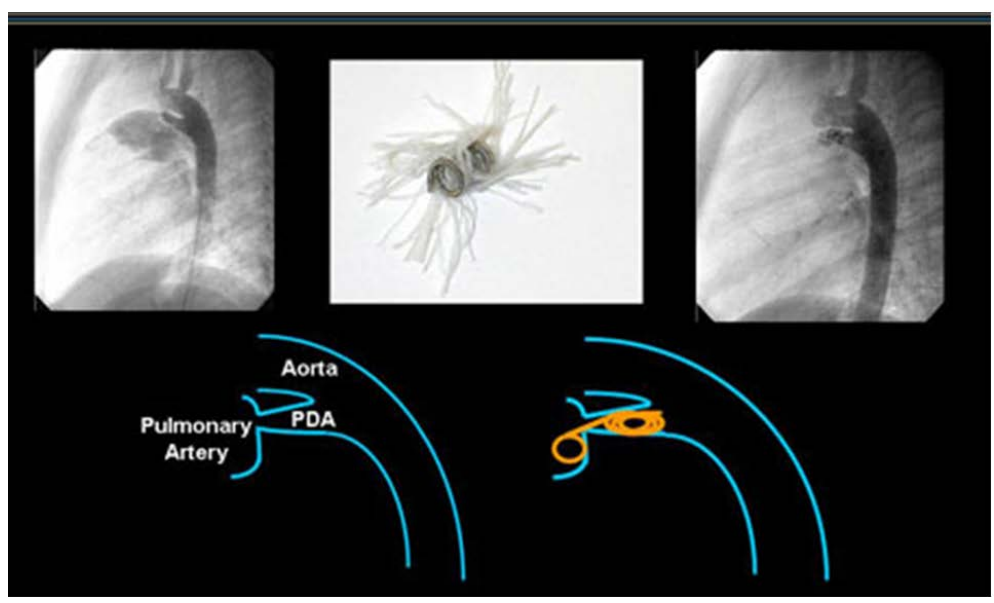

Figure 9. Fluroscopic image of patent ductus arteriosus closure with coil embolisation.

ity of the patient due to the C-arm. Potential lack of space around the patient also limits the work environment of the anaesthetic team.

\section{Conclusion}

The often complex nature of the patient and the intervention demand meticulous planning on behalf of the anaesthesiologist to ensure a reasonable plan for the anaesthesia, monitoring, venous access, additional equipment required and potential complications of the procedure. Anaesthesiologists are assuming an increasingly important role in the multidisciplinary management of these cases. A comprehensive understanding of these procedures is essential to provide a high level of anaesthetic care and maintain patient safety.

\section{Financial Support}

This research received no specific grant from any funding agency, commercial or not-for-profit sectors.

\section{Conflict of Interest}

None.

\section{References}

[1] Braithwaite, S., Kluin, J., Buhre, W.F. and de Waal, E. (2010) Anaesthesia in the Cardiac Catheterization Laboratory. Current Opinion in Anaesthesiology, 23, 507-512. http://dx.doi.org/10.1097/ACO.0b013e32833bb5e4

[2] Shook, D.C. and Savage, R.M. (2009) Anaesthesia in the Cardiac Catheterization Laboratory and Electrophysiology Laboratory. Anaesthesiology Clinics, 27, 47-56. http://dx.doi.org/10.1016/j.anclin.2008.10.011

[3] Hayman, M., Forrest, P. and Kam, P. (2012) Anaesthesia for Interventional Cardiology. Journal of Cardiothoracic and Vascular Anaesthesia, 26, 134-147. http://dx.doi.org/10.1053/j.jvca.2011.09.004

[4] Shook, D.C. and Gross, W. (2007) Offsite Anaesthesiology in the Cardiac Catheterization Laboratory. Current Opinion in Anaesthesiology, 20, 352-358. http://dx.doi.org/10.1097/ACO.0b013e32827ab47b

[5] (2002) American Society of Anaesthesiologists. Task Force on Sedation and Analgesia by Non Anaesthesiologists. Practice Guidelines for Sedation and Analgesia by Non Anaesthesiologists. Anaesthesiology, 96, 1004-1017. http://dx.doi.org/10.1097/00000542-200204000-00031

[6] (2003) Statement on Nonoperating Room Anaesthetizing Locations Committee of Origin: Standards and Practice Parameters Approved by the ASA House of Delegates on October 15, 2003.

[7] Klemm, H.U., Steven, D., Johnsen, C., et al. (2007) Catheter Motion during Atrial Ablation Due to the Beating Heart and Respiration: Impact on Accuracy and Spatial Referencing in Three-Dimensional Mapping. Heart Rhythm, 4, 587592. http://dx.doi.org/10.1016/j.hrthm.2007.01.016

[8] Di Biase, L., Conti, S., Mohanty, P., et al. (2011) General Anaesthesia Reduces the Prevalence of Pulmonary Vein 
Reconnection during Repeat Ablation When Compared with Conscious Sedation. Results from a Randomized Study. Heart Rhythm, 8, 368-372. http://dx.doi.org/10.1016/j.hrthm.2010.10.043

[9] Viskin, S. (1999) Long QT Syndromes and Torsade de Pointes. Lancet, 354, 1625-1633. http://dx.doi.org/10.1016/S0140-6736(99)02107-8

[10] Kang, J., Reynolds, W.P., Chen, X.L., et al. (2006) Mechanisms Underlying the QT Interval-Prolonging Effects of Sevoflurane and Its Interactions with Other QT-Prolonging Drugs. Anaesthesiology, 104, 1015-1022. http://dx.doi.org/10.1097/00000542-200605000-00018

[11] Higashijima, U., Terao, Y., Ichinomiya, T., Miura1, K., Fukusaki, M. and Sumikawa, K. (2010) A Comparison of the Effect on QT Interval between Thiamylal and Propofol during Anaesthetic Induction. Anaesthesia, 65, 679-683.

[12] Serruys, P.W., Kutryk, M.J. and Ong, A.T. (2006) Coronary Artery Stents. The New England Journal of Medicine, 354, 483-495. http://dx.doi.org/10.1056/NEJMra051091

[13] Moses, J.W., Leon, M.B., Popma, J.J., Fitzgerald, P.J., Holmes, D.R. and O’Shaughnessy, C., et al. (2003) Sirolimus-Eluting Stents versus Standard Stents in Patients with Stenosis in a Native Coronary Artery. The New England Journal of Medicine, 349, 1315-1323. http://dx.doi.org/10.1056/NEJMoa035071

[14] Grube, E., Silber, S., Hauptmann, K.E., Mueller, R., Buellesfeld, L., Gerckens, U. and Russell, M.E. (2003) TAXUS I: Six and Twelve Month Results from a Randomized Double Blind Trial on a Slow Release Paclitaxel-Eluting Stent for De Novo Coronary Lesions. Circulation, 107, 38-42. http://dx.doi.org/10.1161/01.CIR.0000047700.58683.A1

[15] Arrich, J., Holzer, M., Havel, C., Müllner, M. and Herkner, H. (2012) Hypothermia for Neuroprotection in Adults after Cardiopulmonary Resuscitation. Cochrane Database of Systematic Reviews, Published Online.

[16] King, T.D., Thompson, S.L., Steiner, C. and Mills, N.L. (1976) Secundum Atrial Septal Defect. Non Operative Closure during Cardiac Catheterization. Journal of the American Medical Association, 235, 2506-2509. http://dx.doi.org/10.1001/jama.1976.03260490024013

[17] Hollinger, I. and Mittnacht, A. (2009) Cardiac Catheterization Laboratory: Catheterization, Interventional Cardiology and Ablation Techniques for Children. International Anesthesiology Clinics, 47, 63-99. http://dx.doi.org/10.1097/AIA.0b013e31819417d7

[18] Martinez, M.W., Mookadam, F., Sun, Y. and Hagler, D.J. (2007) Transcatheter Closure of Ischemic and Post Traumatic Ventricular Septal Ruptures. Catheterization and Cardiovascular Interventions, 69, 403-407. http://dx.doi.org/10.1002/ccd.20949

[19] Garay, F., Cao, Q.L. and Hjazi, Z.M. (2006) Percutaneous Closure of Post Myocardial Infarction Ventricular Septal Defect. Journal of Interventional Cardiology, 19, 67-72. http://dx.doi.org/10.1111/j.1540-8183.2006.00173.x

[20] Cribier, A., Eltchaninoff, H., Bash, A., Borenstein, N., Tron, C., Bauer, F., et al. (2002) Percutaneous Transcatheter Implantation of an Aortic Valve Prosthesis for Calcific Aortic Stenosis: First Human Case Description. Circulation, 106, 3006-3008.

[21] Block, P.C. (2006) Percutaneous Transcatheter Repair for Mitral Regurgitation. Journal of Interventional Cardiology, 19, 547-551. http://dx.doi.org/10.1111/j.1540-8183.2006.00209.x

[22] Feldman, T. (2007) Percutaneous Mitral Valve Repair. Journal of Interventional Cardiology, 20, 488-494. http://dx.doi.org/10.1111/j.1540-8183.2007.00295.x

[23] Nobuyoshi, M., Arita, T., Shirai, S., Hamasaki, N., Yokoi, H., Iwabuchi, M., et al. (2009) Percutaneous Balloon Mitral Valvuloplasty: A Review. Circulation, 119, e211-e219. http://dx.doi.org/10.1161/CIRCULATIONAHA.108.792952

[24] Kar, B., Adkins, L.E., Civitello, A.B., Loyalka, P., Palanichamy, N., Gemmato, C.J., et al. (2006) Clinical Experience with the Tandem Heart Percutaneous Ventricular Assist Device. Texas Heart Institute Journal, 33, 111-115.

[25] Pretorius, M., Hughes, A.K., Stahlman, M.B., Saavedra, P.J., Deegan, R.J., Greelish, J.P. and Zhao, D.X. (2006) Placement of the Tandem Heart Percutaneous Left Ventricular Assist Device. Anesthesia \& Analgesia, 103, 1412-1413. http://dx.doi.org/10.1213/01.ane.0000243330.74987.28

[26] Spina, R., Forrest, A.P., Adams, M.R., Wilson, M.K., Ng, M.K. and Vallely, M.P. (2010) Veno-Arterial Extracorporeal Membrane Oxygenation for High-Risk Cardiac Catheterisation Procedures. Heart, Lung and Circulation, 19, 736-741. http://dx.doi.org/10.1016/j.hlc.2010.08.015

[27] Meyer, J., Mollhalt, I., Seiter, T., Brunn, J., Rötker, J., Block, M. and Prien, T. (1996) Cardiac Output Is Not Affected during Intraoperative Testing of the Automatic Implantable Cardioverter Defibrillator. Journal of Cardiovascular Electrophysiology, 7, 211-216. http://dx.doi.org/10.1111/j.1540-8167.1996.tb00518.x

[28] Gilbert, T.B., Gold, M.B., Shorofsky, S.R., Hasnain, J.U., Ferguson, M.K. and Foster, A.H. (2002) Cardiovascular Responses to Repetitive Defibrillation during Implantable Cardioverter-Defibrillator Testing. Journal of Cardiothoracic and Vascular Anesthesia, 16, 180-185. http://dx.doi.org/10.1053/jcan.2002.31061

[29] Farooqi, F.M., Talsania, S., Hamid, S. and Rinaldi, C.A. (2010) Extraction of Cardiac Rhythm Devices: Indications, 
Techniques and Outcomes for the Removal of Pacemaker and Defibrillator Leads. International Journal of Clinical Practice, 64, 1140-1147. http://dx.doi.org/10.1111/j.1742-1241.2010.02338.X

[30] Masura, J., Walsh, K.P., Thanopoulous, B., Chan, C., Bass, J., Goussous, Y., et al. (1998) Catheter Closure of Moderate- to Large-Sized Patent Ductus Arteriosus Using the New Amplatzer Duct Occluder: Immediate and Short-Term Results. Journal of the American College of Cardiology, 31, 878-882. http://dx.doi.org/10.1016/S0735-1097(98)00013-8 
Scientific Research Publishing (SCIRP) is one of the largest Open Access journal publishers. It is currently publishing more than 200 open access, online, peer-reviewed journals covering a wide range of academic disciplines. SCIRP serves the worldwide academic communities and contributes to the progress and application of science with its publication.

Other selected journals from SCIRP are listed as below. Submit your manuscript to us via either submit@scirp.org or Online Submission Portal.
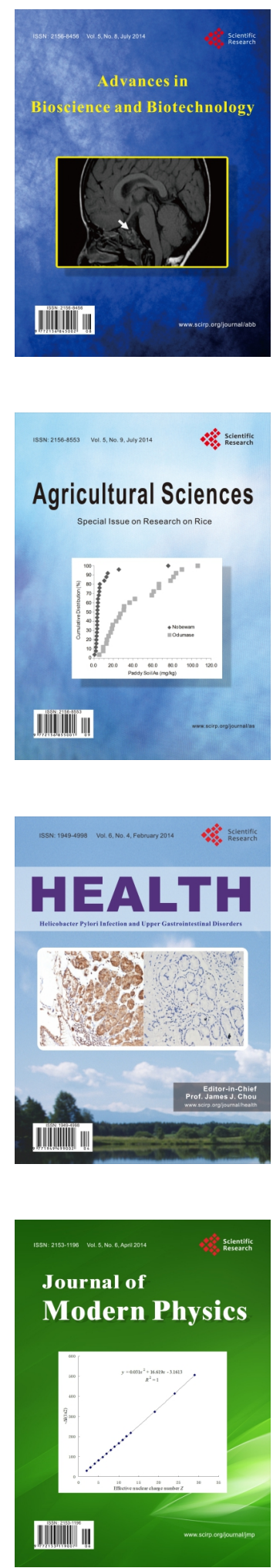
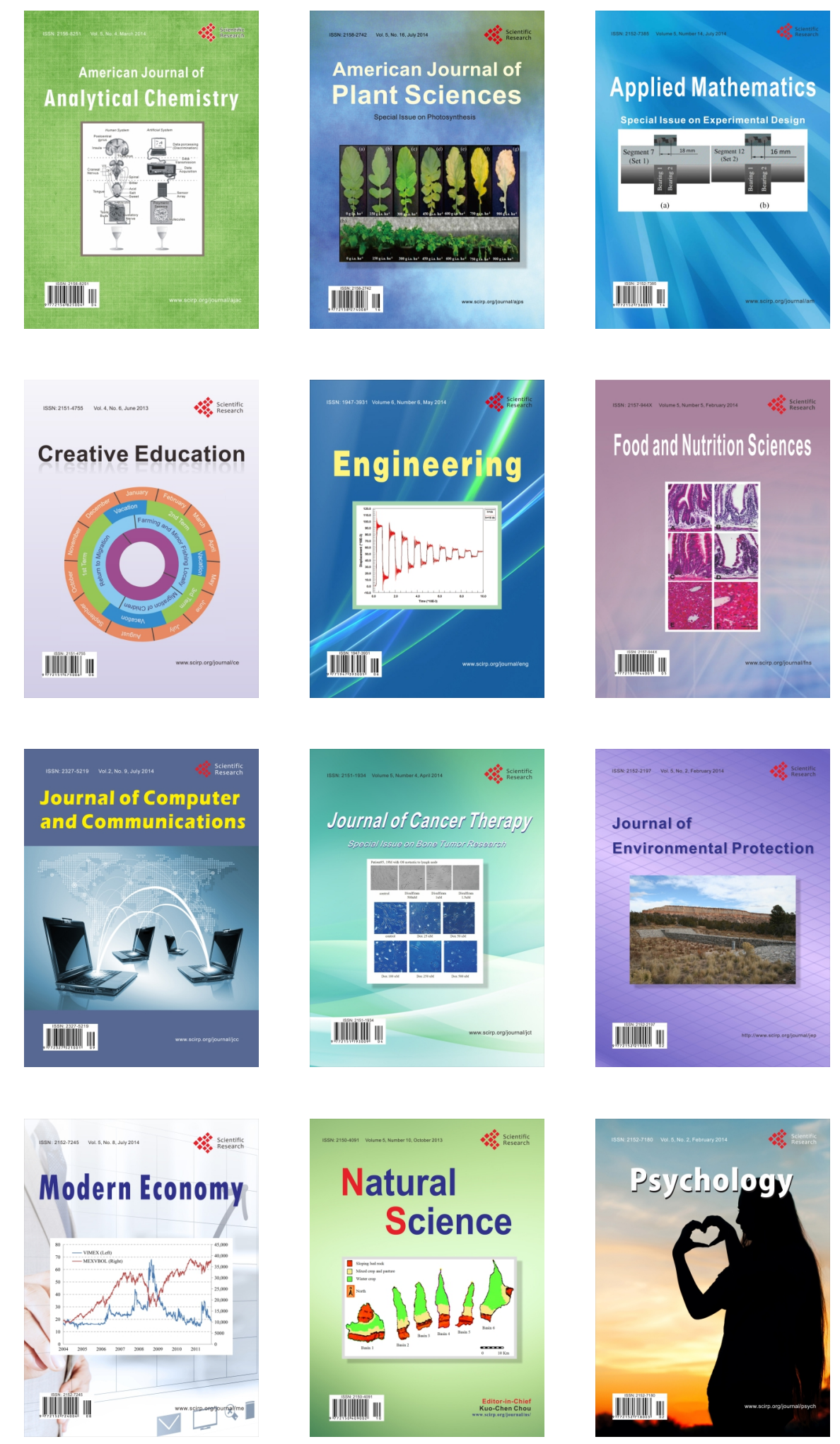